\title{
Exploring perceptions of instructors about childbirth preparation training courses: A qualitative study
}

Marzieh Otogara ${ }^{1}$, Akram Karimi-Shahanjarini² ${ }^{2}$, Seyed Mohammad Mehdi Hazavehei ${ }^{3}$, Jalal Poorolajal ${ }^{4}$, Nahid Radnia $^{5}$, Forouzan Akrami ${ }^{6}$, Fahimeh Bagheri ${ }^{1}$

${ }^{1}$ Ph.D. Student of Health Education and Promotion, Department of Public Health, School of Public Health, Hamadan University of Medical Sciences, Hamadan, Iran

${ }^{2}$ Ph.D. of Health Education, Associate Professor, Social Determinates of Health Research Center and Department of Public Health, School of Public Health, Hamadan University of Medical Sciences, Hamadan, Iran

${ }^{3}$ Ph.D. of Health Education, Professor, Research Center for Health Sciences and Department of Public Health, School of Public Health, Hamadan University of Medical Sciences, Hamadan, Iran

${ }^{4}$ Ph.D. of Epidemiology, Associate Professor, Department of Epidemiology, School of Public Health, Hamadan University of Medical Sciences, Hamadan, Iran

${ }^{5}$ M.D., Gynecologist, Assistant Professor, Department of Gynecology, School of Medicine, Hamadan University of Medical Sciences, Hamadan, Iran

${ }^{6}$ Ph.D. by Research Student, Medical Ethics and Law Research Center, Shahid Beheshti University of Medical Sciences, Tehran, Iran

\section{Type of article: Original}

\begin{abstract}
Background: Childbirth preparation training courses on maternal and neonatal health increase awareness, and capability of pregnant women in overcoming fear and anxiety and managing labor pains.

Objective: To identify the affecting factors and barriers of these courses from the perspective of their instructors. Methods: This qualitative study of the content analysis type, has been conducted on 16 certified teachers of the training courses of the Hamadan city in 2015. Data were collected by semi-structured in-depth interviews and were then analyzed by using MAXQDA10 application.

Results: Participants' experiences are indicated on three main themes including the objectives of the course, facilitators and barriers. The main objectives of the course were reported as to improve maternal and newborn health, promote natural childbirth and preparedness for parenting and breastfeeding. The main facilitators of the successful implementation include observing educational standards, strengthening the communication and relationship between mothers and staff, mobilization, and the role of instructor. The major barriers are reported as inadequate support from management system, insufficient intra-sector collaboration, poor attitude of obstetricians and physicians, inadequate access, theory-practice gap and not intended to labor naturally.

Conclusion: The results of our study show that multiple factors are involved in the participation of pregnant women in antenatal classes. Promoting natural childbirth requires intra-sector and inter-sectoral collaboration, as well as the community participation.
\end{abstract}

Keywords: Pregnancy, Childbirth, Education, Qualitative study

\section{Introduction}

Pregnancy and childbirth is a natural process and an important event in the life of every woman (1). Although vaginal delivery is still considered as standard of care (2), in recent decades, a significant increase of interest in cesarean section (CS) in the absence of any medical indications has occurred. A phenomenon that causes an increase in CS and its planning has been a public health problem in the general population $(2,3)$, in as far as rates increased

\section{Corresponding author:}

Associate Professor Akram Karimi-Shahanjarini, Social Determinates of Health Research Center and Department of Public Health, School of Public Health, Hamadan University of Medical Sciences, Hamadan, Iran.

Tel: +98.8138380583, Email: karimi.a@umsha.ac.ir

Received: September 06, 2016, Accepted: February 14, 2017, Published: April 2017

iThenticate screening: February 13, 2017, English editing: April 01, 2017, Quality control: April 12, 2017

(C) 2017 The Authors. This is an open access article under the terms of the Creative Commons Attribution-NonCommercialNoDerivs License, which permits use and distribution in any medium, provided the original work is properly cited, the use is non-commercial and no modifications or adaptations are made. 
globally from 5 to 25 percent (4). While, according to the World Health Organization CS rates should be any more than 15 percent. This increase reflects two trends at once: An increase in primary CS, and cesarean repeat following primary cesarean (5). Maternal health is accounted as a vital, social and economic investment which for this important case, health services including high-quality care and education should be available to mothers (6). According to the national system of birth registration, the CS rate has increased to 56 percent and its percentage is related to cesarean choice (7). The rate of cesarean in a meta-analysis (2014) in Iran, reported 48 percent which is more than three times the global standard (8). The cesarean rate in Hamadan province in 2014 reached 47.8 percent (9). Several medical and non-medical factors such as fear of labor pain and attitude to child birth contributing to high cesarean rates are involved in CS, so that the support of instructors has had significant effect on the reduction of the primary and repeated cesareans (10). For example, based on previous studies, the most common reason for cesarean demand for nulliparous women is the fear of natural childbirth, and it is estimated that out of every 5 pregnant women, one has a fear of natural childbirth and in most women, fear of birth leads to increased anxiety, pain, and prolonged labor (11-13). Antenatal education is a dynamic process in which parents receive information about the physical and emotional changes of pregnancy, childbirth, and neuromuscular and parental training in labor support techniques. Antenatal classes have been shown to have an effect in reducing the fear and anxiety during labor (14). Yilmaz et al. also showed the impact of traditional measures in order to facilitate women's labor in Turkey (15). Due to the high rate of CS and medical interventions, preparation of pregnancy and physiologic childbirth classes were designed and have been implemented in selected hospitals in the country since 2007. Maternity hospitals in Hamadan also started holding these classes in 2011 and continue to do so. The course includes eight sessions that start from week 20 of pregnancy, and training is done by midwives who have passed the 60-hour short-term course of physiologic childbirth. Integrated maternal health care program evaluation in 2012 showed that despite the effectiveness of the program, there was still work needed to be done on ways of educating others about childbirth and postpartum care (16). Due to medicalization of childbirth, we need to identify the effective factors and barriers of education. Lack of awareness and readiness of the expectant mother is a major cause of medical intervention and birth complications for both the mother and the newborn. Various studies have shown that taking childbirth preparation classes is an opportunity to gain maternal education, decrease low back pain and fatigue so that it allows an increase in daily activity and promotes a healthy marital relationship. Other studies have also indicated the protective effect of childbirth preparation classes (17). Gupta et al. found that child birth preparation classes reduce the duration of the labor and birth stages (18). A study showed that group discussion is more effective than the lecture method in increasing knowledge, attitude and practice of pregnant women about normal vaginal delivery (NVD) (19). In another study on the barriers of patient education in clinical care, participants reported the barriers in three dimensions of management, care and patient, and management was known as the main factor (20). Due to the atmosphere of childbirth and the lack of evidence-based care action in Iran, exclusively, the need for a comprehensive educational program for childbirth is confirmed. In addition, the need for a health care system to be more accountable for the establishment of training programs for pregnant women has been pointed out (21). Because of the main role of childbirth instructors is in increasing the mothers' knowledge, attitude and preparedness for childbearing and parenting, this study aimed to explore the perception of the instructors about childbirth preparation training courses. Identifying the barriers, facilitators and other factors affecting the success of childbirth courses can help us to promote NVD and remove its barriers.

\section{Material and Methods}

This qualitative study with directed content analysis approach was done on certified instructors of birth preparedness, with at least six months' experience in teaching courses of physiologic delivery at Hamadan maternity hospitals, in 2015. Purposeful sampling method was used for selecting participants. To collect data, semi-structured in-depth interviews were done with 16 training midwives. Before each interview, in a previous meeting, the study purpose, questions, and confidentiality of information for each participant was explained and if they were willing to participate in the study, an appointment was made. The location of the interview was a classroom and the interviews commenced 15 minutes after the classes. After obtaining permission from the participant, notes of their responses were taken and recorded at the same time. All interviews were conducted individually by the researcher and each interview took 20 to 30 minutes. Interviews continued until the arrival of another person in the study, no new information was obtained and data was saturated (22). The questions of the interview were as follows: In your opinion, what should the main objectives of the course for pregnant women (childbirth preparation classes) be focused on?

1) In your opinion, what are the success factors of these classes?

2) In your opinion, what are the implementation barriers of these classes?

3) What are your suggestions for greater success in these classes? 
According to Guba and Lincoln, for practical strength of the findings, the four criteria of Trustworthiness include validity, verifiability, reliability and transferability. Credibility, confirmability, dependability and transferability were applied (23). It was endeavored that the participants, in terms of age, employment status, work history, education and occupational status had the necessary diversity for creating diverse data. Prolonged engagement, long time presence and intimate relationship of the interviewer with the participants, facilitated the possibility of collecting actual data. Authentication of data was obtained through hand-written reviews by the participants to interpret the coding. For this purpose, the researcher gave parts of the interview and coding to them to achieve similar concepts in relation to statements made by the participants. Then, the credibility between themes extracted by comparing the experiences of participants and the accuracy of coding, classifying similar codes and interpretations were ensured, and codes that the members did not indicate their attitude, were modified and thus, ambiguities and contradictions were solved. The confirmability was conducted by recording and writing processes, and accurate process of research and obeying neutrality. For dependability, findings with experts who were in similar situations with the participants were shared and it was ensured that the findings and experiences were adapted. Transferability was observed by using the opinions of experts (external check) and the entire review of data, as well as providing direct quotes and examples as it was said. Transcript of interviews, after each interview, were carefully listened to several times and were typed in Microsoft Word. Data were analyzed using oriented content analysis and the MAXQDA10 software. This research is the result of an approved project at Hamadan University of Medical Sciences and Research Council Ethics Committee (IR.UMSHA.REC.1394.399, code). The willingness of people to participate in the interview constitutes that they were considered for informed consent of participants.

\section{Results}

Of the 16 participants, 43.75 percent were in the age range $30-40$ years, and 15 participants had a maternal bachelor's degree. Most participants were married and had children. Four of them delivered by vaginal and 10 by cesarean, 6 of whom chose caesarean section without medical indication. The most frequent work experience was among participants ranging from 6 to 10 years. Thirteen participants had more than one year of teaching experience. Analysis of data from interviews extracted three main themes including objectives, the facilitators and barriers to participation, and 14 sub-themes (Table 1).

Table 1. List of the extracted themes and sub-themes

\begin{tabular}{|l|l|}
\hline Main theme & Sub-themes \\
\hline Training course objectives & Improving maternal and newborn health \\
\cline { 2 - 3 } & Promoting natural vaginal delivery \\
\cline { 2 - 3 } & Preparedness for parenting and breastfeeding \\
\hline Effective factors and facilitators & Observing educational standards \\
\cline { 2 - 3 } & Strengthening the communication and relationship between mothers and staff \\
\cline { 2 - 3 } & Mobilization \\
\hline & The role of instructor \\
\hline Barriers & Insufficient support from management system \\
\hline & Insufficient intra-sector collaboration \\
\hline & Poor attitude of obstetricians and physicians \\
\hline & Inadequate access \\
\hline & Theory-practice gap \\
\cline { 2 - 2 } & Not intended to labor naturally \\
\hline
\end{tabular}

\subsection{Training course objectives}

This theme was pulled out at the beginning of the interviews because of the importance of the endpoints in planning and management of the courses. According to the participants' experiences, this theme emerged in 3 sub-themes of improving maternal and newborn health, promoting vaginal delivery, and parenting role.

3.1.1. Improving maternal and newborn health

All participants pointed out that this training course, by increasing awareness and correcting false beliefs of the mothers, can decrease the amount of unnecessary medical interventions during childbirth and help them to lead a healthy birth: "Healthy mothers with healthy newborns without having complications" (Lecturer 1, 4 years teaching experience with 25 years' work experience, and experience of CS).

\subsubsection{Promoting natural vaginal delivery}


Regarding anxiety and fear of the delivery pain as the highest cause to choose CS, the participants believed that lack of knowledge and fear of the unknown creates fear and anxiety in mothers. Pregnant women, during training with the required information about pregnancy, breathing exercises and relaxation and delivery process, and also visiting the maternity ward, are more prepared to control anxiety and labor self-management, and are empowered to overcome the pregnancy and labor with the least complications, and thus, are encouraged to select NVD. "Raising awareness and reducing anxiety and fear caused by low awareness has caused them to choose CS. As soon as they become aware and learn methods to reduce pain, fear of vaginal delivery leading to CS is gone" (lecturer 13, 3 years teaching experience with 15 years' work experience, and experience in NVD). "I think mothers are aware of their pain-relief methods and are inclined to natural delivery " (lecturer 2, 3 years teaching experience with 15 years' work experience, and experience of CS).

\subsubsection{Preparedness for the role of parenting and breastfeeding}

One of the mothers' concerns is about playing the role of motherhood, infant care and breastfeeding, so much so, that participants believed that increasing their preparedness is effective for the concerns about the role of parenting. "They should get information on baby care and breastfeeding and such, in which the mother is usually inexperienced" (lecturer 4, 2 years teaching experience and 8 years' work experience with experience of NVD).

\subsection{Effective factors and facilitators}

This theme has been formed by the 4 sub-themes: standards of training, strengthening the relationship between mothers and staff, mobilization and the role of teachers.

\subsubsection{Observing educational standards}

Participants believed that standardization of the class structure include training materials and tools, content and method of education, starting classes earlier than the 12th week of pregnancy, increasing the number of practical sessions especially for improvement of attendant person skills, and the presence of a psychologist all play an important role in the successful implementation of the training course. All participants understood the educational content as sufficient and appropriate with weeks of pregnancy. "Classes should be standard and have all the necessary facilities" (Lecturer 1, 4 years teaching experience with 25 years' work experience, and experience of CS). "Furniture should be suitable and the seating area should be larger with appropriate ventilation and the exam and hall facilities should be good enough to be able to give an adequate explanation" (Lecturer 11, 2 years teaching experience with 14 years' work experience, and experience of CS). They believed that according to the protocol, at maximum 10 pregnant women and their attendants must participate in each session, so increasing the number of participants decreases the efficiency of classes. "The right number of mothers that we should be able to answer questions for is important, classes must have high quality rather than having many people and low quality classes. Many instructors do not succeed because they become tired" (Teacher 1, 3 years teaching experience; 9 years' work experience with CS experience). One participant who mentioned the importance of class attraction, especially at the first meeting states that: "Education should be good at the first session, contents should be interesting for mothers, mothers' questions should be answered so that, the last quarter of the session is dedicated to it, and also, relaxation should be a part of the session. These issues encourage mothers to be interested in the class" (Lecturer 9, 1 year teaching experience with 8 years' work experience, NVD experience). "The number of meetings should be increased, especially for the exercise sessions (with pause), at least having one practical session per week is very important, and also for attendants so that they learn how to massage and support the mother". (Lecturer 6, 3 years teaching experience with 12 years' work experience, and experience of CS). They also believed that education should lead to empowerment so that, pregnant women, by using self- management skills of the mind and body are able to enjoy the dynamic relaxation. "Psychologic counseling should exist to eliminate the root cause of fear and the class should be managed by a team" "(Lecturer 12, two years teaching experience with 8 years' work experience, experience of NVD).

\subsubsection{Strengthening the communication and relationship between mothers and staff}

Participants also stated that strengthening the relationship between mother and staff is one of the advantages of the training course that facilitates natural childbirth. "Once they have stronger links with the staff, they will also have better cooperation at the time of delivery" (lecturer 8, 2 years teaching experience with 20 years' work experience, and experience of CS).

\subsubsection{Mobilization}

Due to medicalization of childbirth and need for public sensitization and awareness, participants believed that informing must be a collective endeavor and all organizations, particularly the public media should be involved. One of the participants stated: "It should be more advertised that the classes exist, should be more informed of in the media" (Lecturer 10, 4 years teaching experience with 25 years' work experience, and experience of CS). One of the interviewees gave an interesting example in this context: "All organizations need to work together seamlessly until 
all the people find out about this plan. Like elections which decorate the entire city and everybody is informed. The IRIB, municipalities and governors contribute to each other so that everybody is informed about these classes. Wide spread notification leads to improvement" (lecturer 9, 1 year teaching experience with 8 years' work experience, experience of NVD).

\subsubsection{The role of instructor}

Because of transferring instructors' beliefs to the participants through training, simultaneously, their role in changing and developing positive attitudes is an effective factor. Participants believed that it was necessary for instructors to be familiar with different educational methods, and apply different methods such as group discussion in childbirth preparation classes. "Explain simply for mothers and know the education principles. For instance, I sometimes put someone else instead of me and after, in the next session, they say that she didn't explain some things as you are saying, when you explain we understand much better because I try to tell my experiences in a way that they can understand" (lecturer 2, 3 years teaching experience with 15 years' work experience, and experience of CS). One of them told about the work experience as: "they should work in labor and delivery wards as their work experience is very important to be able to transfer this experience to the mother. Say what will happen in labor and explain their work" (Lecturer 5, 4 years teaching experience with 23 years' work experience, and experience of CS). This kind of education needs belief in natural birth as a safe and healthy method. Most participants stated that education is an art, needs interest and love, and in addition to verbal skills, an instructor must be able to use nonverbal skills as well as techniques to interact with people so that, classes are successful in achieving the objectives of the course. "It's important from a rhetorical view and when the instructor builds a nice relationship with the mother, it's beneficial for the mother and she must have a good expression and the instructor must have great communication with the mother, so they talk together with ease and the mother shouldn't feel in a way that when she wants to ask a question it might probably be bad, and it should be comfortable" (lecturer 11, 2 years of teaching experience with 14 years of experience, and experience of cesarean delivery). Someone believed that their instructors who have experienced NVD, are a better model for pregnant women and can further affect them. "If she has gone through pregnancy before and has delivered naturally, she can better relate to mothers" (Lecturer 14, 3 years teaching experience with 15 years' work experience, and experience of CS). Being up to date and having work experience in maternity and labor wards helps instructors to facilitate knowledge diffusion and translation. Most participants believed that the instructor should be able to answer the mothers' questions and have enough experience for teaching. One of them says: "The instructor should pass re-training courses and each part of these courses be allocated to a certain topic such as relaxation techniques, it is important teachings be remembered by the instructors" (Lecturer 4, 2 years teaching experience with 8 years' work experience, and experience of NVD). "Because someone has internet access, instructors should introduce proper and valid references to them, and try to give new and useful information". (Lecturer 8, 2 years of teaching experience with 20 years' work experience, and experience of CS). One of them stated: "The instructor should have reached to such understanding that natural birth is good and mothers should be interested in education" (Lecturer 7, 1 years teaching experience with 10 years 'work experience, and experience of CS). Although some participants pointed to the need for diverse teachers, one of the most experienced instructors believed that: "During these sessions it has been proven to me that each group should have a constant instructor, because the information that she starts with can be related to each other in the next sessions and is familiar with mothers and they can feel calm and believe in her words" (Lecturer 10, 4 years teaching experience with 25 years' work experience, experience of CS).

\subsection{Barriers}

This theme has been formed by the 6 sub-themes:

\subsubsection{Insufficient support from management system}

In this study, participants believed that the success of any program involves support from a management system which can provide the necessary resources. They acknowledged that other issues are human resources and their motivation. One of the participants stated that: "The managers should also support these classes and give importance to education and provide learning equipment" (Lecturer 4, 2 years teaching experience with 8 years' work experience, experienced in NVD). Another added that: "the number of people who work in turning shifts are low and since they're not fixed, and forces should be supplied from other sections, their managers might not cooperate with them and their shift is compacted, and supplying forces must exist and everybody must take this course" (Lecturer 7, 1 years teaching experience with 10 years' work experience, experience of CS). In addition to feeling valuable and efficient, timely payment of remuneration in accordance with the approved tariff will increase motivation of instructors. One of them sadly stated: "The most important thing is that the instructor should have motivation, and should be supplied financially and payments should be given at the exact time" (Lecturer 14, 3 years teaching experience with 15 years' work experience, and experience of CS). 


\subsubsection{Insufficient intra-sector collaboration}

Insufficient intra-sector collaboration to on time informing and assigning of pregnant women to the classes is one of the greatest barriers mentioned by most participants. One of the participants, regarding the importance of prenatal care referrals and follow-up by health care providers said: "On time assignment of the pregnant mothers and the contribution of the health centers is also important" (Lecturer 8, 2 years teaching experience with 20 years' work experience, and experience of CS). Another participant mentioned: "look, advertising in health centers is important because most of the mothers are under health centers but few are introduced by them. Health centers do not cooperate with the treatment units and refer mothers at a late time. A mother who's 35 weeks pregnant has not attended classes from the first session, in my opinion these... (Shakes her head). Health centers should receive feedback, ask them whether they have attended the classes and insist and emphasize that they go and advertise" (lecturer 16, one year of teaching experience with 10 years of experience, and experience of CS).

\subsubsection{Poor attitude of obstetricians and physicians}

Because of the key role of the obstetricians in promoting natural childbirth, we consider this issue separately. Participants acknowledged the need to introduce pregnant mothers from obstetricians' offices and their emphasis on attending these classes: "Obstetricians also don't know about these classes and don't advertise. Everybody should be informed about the classes and the physiologic labor" (Lecturer 5, 4 years teaching experience with 23 years' work experience, and experience of CS); "Obstetricians are the first people whose words have impact on the mothers and they must guide them" (Lecturer 11, 2 years teaching experience with 14 years' work experience, and experience of CS). Due to the negative attitude of some obstetricians toward these classes, more than half of the participants have pointed to inform and encourage mothers about antenatal classes and participate in them. "Some women have negative views and don't participate in classes, negative or implied advertising from the gynecologists and even obstetricians that are not active in this ground and also other staff are effective, since they don't have any positive attitude and have a negative perception and don't have any belief, intentionally or unintentionally advertise negatively" (Lecturer 8, 2 years teaching experience with 20 years' work experience, and experience of CS).

\subsubsection{The problem of access}

Participants reported the problem of transportation, especially for rural women in winter as one of the main reasons why pregnant women do not participate in this training course. "Distance and difficulty in the route also exists and rural women can't participate and their distance is far" (Lecturer 2, 3 years teaching experience with 15 years' work experience, and experience of CS). Improper time of classes being held, and its single session only in the morning also causes some employees of pregnant women to not allow them to attend these classes. One of the participants said: "The mother might not be comfortable at 8:30 in the morning and in the cold season, afternoon shifts should be activated and morning sessions should be started at 9:00" (Lecturer 10, 4 years teaching experience with 25 years' work experience, and experience of CS). "The time factor is very important, some pregnant women are employed but since we don't have an afternoon shift, they can't attend the classes" (Lecturer 4, 2 years teaching experience with 8 years' work experience, and experience in NVD).

\subsubsection{Theory-practice gap}

Participants believed that pregnant women should be able to adapt forms of theory learned in classes to practical experience in labor and delivery. "One who is ready for labor sees that the things that have been learnt have not been done, thus, they don't tell the latter groups to come, and the practices in the labor ward must be in relation to the classes" (Lecturer 10, 4 years teaching experience with 25 years' work experience, and experience of CS). "They get feedback from others telling them that the maternity ward is not commensurate with the education and they say they have been examined a lot, though they learn in classes that they shouldn't intervene much and they can't bring it along with them" (Lecturer 5, 4 years of teaching experience with 23 years' work experience, and experience of CS).

\subsubsection{Not intended to labor naturally}

Participants believed that the perception is that physiologic childbirth preparation courses are for those who want to give birth naturally. While, according to the categorization of training sessions, all pregnant women regardless of whether they desire to deliver naturally or by CS should participate in the classes: "It might be because they don't want to give birth naturally and they have fear because they think it's only related to natural childbirth" (Lecturer 16, 1 year teaching experience with 10 years' work experience, and experience of CS). "It's beneficial, in fact people who are going to cesarean and repeat cesarean should come and attend the classes. These are really important. Of course everybody should come, but the ones who are going to cesarean are more important, if the subjects are understood well and it changes their view and attitude, and since subjects are heard and views might be corrected, it's really important, of course it's not intended to cause fear. All the mothers should participate whether they have CS or not, because some things that are being said in the classes are for everyone. For example, everybody should know their diet, warning of mental health symptoms and all the subjects that are said in the class, there's no 
difference, and even know of problems before labor or they should know postpartum, and the subjects are useful for everyone" (Lecturer 5, 4 years teaching experience with 23 years' work experience, and experience of CS).

\section{Discussion}

According to the research questions, data was categorized into three themes including course objectives, facilitators and barriers to participation of pregnant women in classes. The first objective of these classes emerged as "improving maternal and neonatal health" which is compatible with the goal of the formation of the baby-friendly and Mother-Friendly Childbirth Initiatives. Regarding the increasing rates of CS, the second focused on "promotion of natural childbirth". This objective is consistent with the "Step 6: Limits interventions" of ten Steps of the MotherFriendly Childbirth Initiative for Mother-Friendly Hospitals (24). The second objective "preparedness for the role of parenting and breastfeeding" which is compatible with "Step 8: Encourages all mothers, families to touch, hold, breastfeed and care for their babies" (24). Our findings were also similar to other studies to raise awareness in coping with stress and anxiety and less intervention, ongoing support of the mother and improving maternal and neonatal health and mother's familiarity with the methods of pain relief and pain management skills $(14,25-29)$. The results suggest that in the successful implementation of training courses, factors such as observing standards (i.e. the number of participants attending the class and consultant psychologist), mobilization, strengthening the relationship between mothers and staff and the role of the instructor are involved. De Joy (2010) found similar results about obstetricians and labor in studying students' beliefs (30). Several studies have shown that space and equipment and access to training facilities play an important role in learning, and that psychotherapy training programs for pregnancy problems is also effective in relieving mental issues $(31,32)$. The results showed that the sub-themes of mobilization and participation of other organizations is an important factor to encourage mothers to participate in classes and achieve the main objectives. In regards to highlighting the role of instructors in our study, it should be acknowledged that understanding factors such as education principles and methods, knowledge, interest and communication skills as well as their experience has been confirmed in several studies (33). Taheri et al. also found that good communication improves the effectiveness of education (34). However, some studies also have pointed to other factors such as conscience (35). Taghi-Zadeh et al. observed a significant correlation between client satisfaction and the amount of verbal and nonverbal communication skills by midwives (36). Based on our findings, sub-themes of barriers to participation consist of 6 groups: Insufficient support of management system, insufficient intra-sector collaboration, poor attitude of obstetricians and physicians, inadequate access, theory-practice gap and not intended to labor naturally. Yazdizadeh et al. and Challiet et al. also found similar results $(37,38)$. Taghizadegan et al. and Saeidpour et al. also mentioned the manpower shortage and poor support systems as the most important barriers $(39,40)$. O'Donnell et al., in their study on quality of care provided during childbirth reported the availability of resources, motivation and empowerment of the staff as the factors affecting the quality of care (41). Hence, the goal of mother-friendly childbirth initiative was to foster collaboration in a national effort to promote natural childbirth and breastfeeding (24). One of the approaches to achieve health equity, is equal access to basic health services through action on the social determinants of health. In our study, difficulty of transportation and unsuitable time for attending classes were barriers to participate in classes. The results of our study are consistent with previous studies $(42,43)$. Therefore, this problem implies the need for equal geographic distribution of classes, providing the necessary manpower, and holding it in morning and afternoon shifts. Negative attitudes of service providers, was one of the major limiting factors in this study. Studies on the professional role of obstetricians have shown their attitude to the type of delivery (44). Heatley and Krukse specified that cooperation among different specialists in safe maternal care is an important issue (45). Another drawback is having no intention to natural delivery. It is thought that according to its title, this course is only for those who intend to have childbirth naturally. And this, despite the fact that according to categories of educational sessions, all pregnant women, regardless of whether a candidate for NVD or CS should participate in these classes. Therefore, the correct name and notification period, and also proper planning for the proposed objectives by leveraging on the needs of target groups is necessary in this regard. Finally, we explore experiences of participants based on their perceptions, and since individual and environmental conditions of training and also governing politics in each situation effects participants' explanations, the findings may not be generalizable to other situations.

\section{Conclusions}

The results of our study show that multiple factors are involved in the participation of pregnant women in childbirth classes. In such a way that promoting natural childbirth, needs intra-sector and inter-sectoral collaboration, and also the participation of society. Therefore, it is necessary for planners and administrators at each university with the support and resources required, to adopt necessary measures to support the holding of this training course, 
standardization, and access to services, promoting and removing barriers with the other interventions of the healthcare reform plan.

\section{Acknowledgments:}

This study is one part of the PhD thesis in the field of health education and promotion. The authors would like to thank the Vice-Chancellor of Research and Technology of Hamadan University of Medical Sciences for supporting the study.

\section{Conflict of Interest:}

There is no conflict of interest to be declared.

\section{Authors' contributions:}

All authors contributed to this project and article equally. All authors read and approved the final manuscript.

\section{References:}

1) Mehdizadeh A, Roosta F, Kamali Z, Khoshgoo N. Evaluation of the effectiveness of antenatal preparation for childbirth courses on the health of the mother and the newborn. Razi Journal of Medical Sciences. 2003; 10(35): 455-61.

2) Minkoff H, Chervenak FA. Elective primary cesarean delivery. N Engl J Med. 2003; 348(10): 946-50. doi: 10.1056/NEJMsb022734. PMID: 12621140.

3) Plante LA. Public health implications of cesarean on demand. Obstet Gynecol Surv. 2006; 61(12): 807-15. doi: 10.1097/01.ogx.0000248826.44123.73. PMID: 17107630.

4) Lauer JA, Betrán AP, Merialdi M, Wojdyla D. Determinants of caesarean section rates in developed countries: supply, demand and opportunities for control. World Health Rep. 2010.

5) Visco AG, Viswanathan M, Lohr KN, Wechter ME, Gartlehner G, Wu JM, et al. Cesarean delivery on maternal request: maternal and neonatal outcomes. Obstet Gynecol. 2006; 108(6): 1517-29. doi: 10.1097/01.AOG.0000241092.79282.87. PMID: 17138788.

6) Freedman LP, Graham WJ, Brazier E, Smith JM, Ensor T, Fauveau V, et al. Practical lessons from global safe motherhood initiatives: time for a new focus on implementation. Lancet. 2007; 370(9595): 1383-91. doi: 10.1016/S0140-6736(07)61581-5. PMID: 17933654.

7) Iranian Ministry Of Health and Medical Education (MOHME). Iranian Maternal and Neonatal registration Network report. In: health N, editor. tehran: Phanohonar; 2012.

8) Azami-Aghdash S, Ghojazadeh M, Dehdilani N, Mohammadi M, Asl Amin Abad R. Prevalence and Causes of Cesarean Section in Iran: Systematic Review and Meta-Analysis. Iran J Public Health. 2014; 43(5): 545-55. PMID: 26060756, PMCID: PMC4449402.

9) Moeini B, Allahverdipour H, Mahjoub H, Bashirian S. Assessing pregnant women's beliefs, behavioral intention and predictive factors for cesarean section in Hamadan. The Iranian Journal of Obstetrics, Gynecology and Infertility. 2011; 14(3): 37-44.

10) Fabri R, Murta EF. Socioeconomic factors and cesarean section rates. I Int J Gynaecol Obstet. 2015; 76(1): 87-8. PMID: 11818102 .

11) Beebe KR, Lee KA, Carrieri - Kohlman V, Humphreys J. The effects of childbirth self - efficacy and anxiety during pregnancy on prehospitalization labor. J Obstet Gynecol Neonatal Nurs. 2007; 36(5): 410-8. doi: 10.1111/j.1552-6909.2007.00170.x. PMID: 17880311.

12) Cheyne H, Abhyankar P, McCourt C. Empowering change: realist evaluation of a Scottish Government programme to support normal birth. Midwifery. 2013; 29(10): 1110-21. doi: 10.1016/j.midw.2013.07.018. PMID: 23968777.

13) Khorsandi M, Ghofranipour F, Heydarnia A, Faghih Zadeh S, Vafaei M, Rousta F, et al. The effect of childbirth preparation classes on childbirth fear and normal delivery among primiparous women. Arak Medical University Journal. 2008; 11(3): 29-36.

14) Najafi F, Abouzari-Gazafroodi K, Jafarzadeh-Kenarsari F, Rahnama P, Gholami Chaboki B. Relationship between attendance at childbirth preparation classes and fear of childbirth and type of delivery. Journal of hayat. 2016; 21(4): 30-40.

15) Yılmaz D, Kısa S, Zeyneloğlu S, Güner T. Determination of the use of traditional practices to ease labour among Turkish women. Int J Nurs Pract. 2013; 19(1): 65-73. doi: 10.1111/ijn.12025. PMID: 23432891. 
16) Akrami F, Mohammadi G, Motlagh ME, Ramezankhani A, Valafar S. Mothers' knowledge, attitude, and practice: The performance of the nationwide integrated maternal health care project. HealthMED. 2012; 6(10): 3316.

17) Greenhalgh R, Slade P, Spiby H. Fathers' coping style, antenatal preparation, and experiences of labor and the postpartum. Birth. 2000; 27(3): 177-84. doi: 10.1046/j.1523-536x.2000.00177.x. PMID: 11251499.

18) Donnelly A, Snowden HM, Renfrew MJ, Woolridge MW. Commercial Hospital Discharge Packs for Breastfeeding Women. Cochrane Database Syst Rev. 2000; (2): CD002075. doi: 10.1002/14651858.CD002075. PMID: 10796281.

19) Ramezankhani A, Akrami F, Heidarzadeh M, Mohammadi G. Comparison of the impact of the two educational methods (lecture and Group Discussion) on knowledge, attitude and behavior intention, and practice of the urban pregnant women; normal vaginal delivery or caesarean? Academic Journal. 2013; 7(5): 1650.

20) Dehghani A, Orang M, Abdollahi Fard S, Parvinian Nasab A, Vejdani M. Barriers to patient education in clinical care; viewpoints of nurses. Iranian Journal of Medical Education. 2014; 14(4): 332-41.

21) TorkZahrani S. Commentary: childbirth education in Iran. J Perinat Educ. 2008; 17(3): 51-4. doi: 10.1624/105812408X329601. PMID: 19436412, PMCID: PMC2517184.

22) Polit DF, Beck CT. Essentials of nursing research: Appraising evidence for nursing practice: Lippincott Williams \& Wilkins; 2010.

23) Polit DF, Beck CT. Essentials of nursing research: Appraising evidence for nursing practice: Lippincott Williams \& Wilkins; 2013.

24) Hotelling BA. The coalition for improving maternity services: Evidence basis for the ten steps of motherfriendly care. J Perinat Educ. 2007; 16(2): 38-43. doi: 10.1624/105812407X197744. PMID: 18311337, PMCID: PMC1905822.

25) Escott D, Spiby H, Slade P, Fraser RB. The range of coping strategies women use to manage pain and anxiety prior to and during first experience of labour. Midwifery. 2004; 20(2): 144-56. doi: 10.1016/j.midw.2003.11.001. PMID: 15177858 .

26) Ferguson S, Davis D, Browne J. Does antenatal education affect labour and birth? A structured review of the literature. Women Birth. 2013; 26(1): e5-8. doi: 10.1016/j.wombi.2012.09.003. PMID: 23063931.

27) Mongan M. Hypnobirthing: The breakthrough natural approach to safer, easier, more comfortable birthingThe Mongan Method. 3rd ed: Health Communications, Inc; 2015.

28) Hodnett ED, Gates S, Hofmeyr GJ, Sakala C, Weston J. Continuous support for women during childbirth. Cochrane Database Syst Rev. 2011; (2): CD003766. doi: 10.1002/14651858.CD003766.pub3. PMID: 21328263

29) Lothian JA. Safe, healthy birth: What every pregnant woman needs to know. J Perinat Educ. 2009; 18(3): 48-54. doi: 10.1624/105812409X461225. PMID: 19750214, PMCID: PMC2730905.

30) DeJoy SB. "Midwives are nice, but...": perceptions of midwifery and childbirth in an undergraduate class. J Midwifery Womens Health. 2010; 55(2): 117-23. doi: 10.1016/j.jmwh.2009.05.009. PMID: 20189130.

31) De Vries CA, De Vries RG. Childbirth education in the 21 st century: An immodest proposal. J Perinat Educ. 2007; 16(4): 38-48. doi: 10.1624/105812407X244958. PMID: 18769525, PMCID: PMC2174394.

32) Gao LL, Chan SW, Li X, Chen S, Hao Y. Evaluation of an interpersonal-psychotherapy-oriented childbirth education programme for Chinese first-time childbearing women: a randomised controlled trial. Int J Nurs Stud. 2010; 47(10): 1208-16. doi: 10.1016/j.ijnurstu.2010.03.002. PMID: 20362992.

33) Geranmayeh M, Rezaeipour A, Haghani H, Akhoondzadeh E. The impact of training on the application of palliative methods for labor pain reduction. Hayat. 2006; 12(2): 13-21.

34) Taheri NK, Karimi Moonaghi H, Dashtgard A. Effects of the nurse-patient communication skill's training on reducing pain in patients. Journal of anesthesiology and pain. 2015; 5(2): 24-32.

35) Firouzbakht M, Nikpour M, Asadi SH. The Effect of Prenatal Education Classes on the Process of Delivery. Journal of Health Breez. 2012; 2(1): 48-55.

36) Taghizadeh Z, Rezaiepour A, Mehran A, Alimoradi Z. Usage of communication skills by midwives and its relation to clients' satisfaction. Journal of hayat. 2007; 12(4): 47-55.

37) Chaillet N, Dubé E, Dugas M, Francoeur D, Dubé J, Gagnon S, et al. Identifying barriers and facilitators towards implementing guidelines to reduce caesarean section rates in Quebec. Bull WHO. 2007; 85(10): $791-7$

38) Yazdizadeh B, Nedjat S, Mohammad K, Rashidian A, Changizi N, Majdzadeh R. Cesarean section rate in Iran, multidimensional approaches for behavioral change of providers: a qualitative study. BMC Health Serv Res. 2011; 11: 159. doi: 10.1186/1472-6963-11-159. PMID: 21729279, PMCID: PMC3146409. 
39) Saeidpour J, Ghazie Askar M, Rahmani H, M. K. Doctors and nurses' point of view regarding facilitators and barriers to patient education. Journal of Hospital. 2014; 13(1): 61-7.

40) Taghizadeh SK, Rahman SA. The Effect of Service Product Innovation Management on Market Performance through Organizational Culture: In Context of Service Product Industry. Retrieved. 2013; 1(1): 1-15.

41) O'Donnell E, Utz B, Khonje D, Van Den Broek N. 'At the right time, in the right way, with the right resources': perceptions of the quality of care provided during childbirth in Malawi. BMC Pregnancy Childbirth. 2014; 14: 248. doi: 10.1186/1471-2393-14-248. PMID: 25069534, PMCID: PMC4133077.

42) Boerleider AW, Wiegers TA, Manniën J, Francke AL, Devillé WL. Factors affecting the use of prenatal care by non-western women in industrialized western countries: a systematic review. BMC Pregnancy Childbirth. 2013; 13: 81. doi: 10.1186/1471-2393-13-81. PMID: 23537172, PMCID: PMC3626532.

43) Fabian H. Women who do not attend parental education classes during pregnancy or after birth: Institutionen för kvinnors och barns hälsa/Department of Women's and Children's Health; 2008.

44) Monari F, Di Mario S, Facchinetti F, Basevi V. Obstetricians' and midwives' attitudes toward cesarean section. Birth. 2008; 35(2): 129-35. doi: 10.1111/j.1523-536X.2008.00226.x. PMID: 18507584.

45) Heatley M, Kruske S. Defining collaboration in Australian maternity care. Women Birth. 2011; 24(2): 537. doi: 10.1016/j.wombi.2011.02.002. PMID: 21382759. 